\title{
INITIAL OUTCOMES OF INTRODUCING THE STUDY OF THE EBOLA VIRUS IN A BIOMEDICAL SCIENCE DEGREE
}

\author{
A. Peña-Fernández ${ }^{1}$, A.J. Broadbent ${ }^{2}$, E.M. Choi ${ }^{3}$ \\ ${ }^{1}$ De Montfort University, Faculty of Health and Life Sciences (UNITED KINGDOM) \\ ${ }^{2}$ The Pirbright Institute (UNITED KINGDOM) \\ ${ }^{3}$ Makeni Government Hospital, Public Health England Laboratory (SIERRA LEONE)
}

\begin{abstract}
The Ebola virus disease (EVD) caused by Zaire ebolavirus (EBOV) primarily affected three countries in West Africa during 2013-2016: Guinea, Liberia and Sierra Leone. The index case was infected in Guinea in December 2013, and subsequently spread to neighbouring countries. According to Ebola Situation Reports from the World Health Organisation, a total of 28,616 Ebola cases were reported in West Africa during the pandemic, with 11,310 deaths. This serious pandemic has highlighted gaps and lack of resources and capabilities in health care systems not only in developing countries but also in Western countries that were impacted when responding to the Ebola outbreak. Thus, serious crossborder biological incidents and outbreaks of infection can dramatically threaten human health. However, they can be can be addressed by providing an effective and rapid response from different experts, health professionals and authorities when there are appropriate tools, capabilities and understanding of these biological hazards. Thus, a series of initiatives were put in place at De Montfort University (DMU, UK) in 2016 to provide appropriate knowledge on infectious diseases to BSc Biomedical Science (BMS) students following the subject-specific threshold standards described by the Quality Assurance Agency (QAA, 2015) [1]. Curriculum changes were undertaken mostly in two modules: Basic Microbiology (level 4), after expanding this to 30 credits in the academic course 2016/17; and Medical Microbiology (level 6; 15 credits). Between the comprehensive curriculum changes performed, one of the changes that raised notable interest in BMS students was the introduction of a lecture/seminar in EBOV following our experience as first responders during the Ebola outbreak working as biomedical scientists in different Ebola laboratories built by Public Health England (PHE) in Sierra Leone. The novel methods for teaching EBOV and haemorrhagic infectious diseases have been previously described by our group in Peña-Fernández et al. $(2016,2017)[2,3]$; briefly we created two sessions with different degrees of difficulties to be delivered to BMS students studying level 4 or 6 , respectively. Students enrolled in Medical Microbiology (level 6) also completed a workshop to respond to outbreaks of infection and protect the public following the steps of evidencebased public health methodology and the lessons learnt when responding to the EBOV outbreak in West Africa in 2015. In this paper we provide a short description of the methods used and recent student feedback collected during the delivery of this workshop in October 2017. The paper will also discuss future improvements that we are undertaking to increase the knowledge of BMS and other health science students including the creation of an e-learning unit to facilitate the study and teaching of EBOV. This novel teaching and learning resource will be publicly available from the DMU website during the first months of 2018; and it is being created following the experience of the development of the first unit for the novel DMU e-Parasitology package [4]. To conclude, the curriculum modifications performed in the BMS programme seemed to facilitate the acquisition of key competences and skills to protect human health in the aftermath of an outbreak of infection.
\end{abstract}

Keywords: Ebola virus outbreak, infectious diseases training, field experience, evidence-based public health, curriculum modifications.

\section{INTRODUCTION}

Ebolavirus is the genus of viruses that causes Ebola virus disease (EVD) traditionally known as Ebola haemorrhagic fever (EHF) in humans. Of the 5 currently known species of Ebolavirus, 4 can cause EVD but only Zaire, Sudan and Bundibugyo have been associated with large outbreaks with personto-person transmissions to date. Zaire ebolavirus (EBOV) was the causative agent of the unprecedented EVD outbreak in West Africa in 2013-2016. The index case was infected in Guinea in December 2013, and subsequently spread to the neighbouring countries Liberia and Sierra Leone [5]. 
According to Ebola Situation Reports from the World Health Organisation, a total of 28,616 Ebola cases were reported in West Africa during the pandemic, with 11,310 deaths [6].

This serious cross-border biological incident dramatically threat human health. However, effective and rapid response from different professionals with the appropriate tools, capabilities and understanding of these biological hazards can face these incidents and minimise morbidity and mortality $[7,8]$. However, insufficient training is provided in Europe to face future crises, particularly amongst clinicians and other health professionals that would be part of the initial response [9]. Thus, our teaching innovation group at De Montfort University (DMU, Leicester, UK) in conjunction with support from EU researchers and first responders (biomedical scientists) during the Ebola outbreak are developing training to respond to biological incidents and outbreak of infection specifically designed for undergraduate human health science students $[2-3,10]$.

Moreover, and in order to provide appropriate knowledge on infectious diseases to BSc Biomedical Science (BMS) students, a series of initiatives were put in place at DMU in 2016 including a series of curriculum changes following the subject-specific threshold standards described by the Quality Assurance Agency (QAA, 2015) [1]. Briefly, changes were undertaken mostly in two modules [11]: Basic Microbiology (level 4), after expanding this to 30 credits in the academic course 2016/17; and Medical Microbiology (level 6; 15 credits). Between the comprehensive curriculum changes performed, one of the changes that raised notable interest in BMS students was the introduction of a lecture/seminar in EBOV following our experience as first responders during the Ebola outbreak working as biomedical scientists in different Ebola laboratories built by Public Health England (PHE) in Sierra Leone (we created two EBOV sessions with different degrees of difficulties to be delivered to BMS students studying level 4 or 6 , respectively) and the completion of a novel workshop to respond to an outbreak of Crimean Congo haemorrhagic fever (CCHF) virus exclusively delivered to final year BMS students in Medical Microbiology, which have been previously described by our group in PeñaFernández et al. (2017) [10]. In this paper we provide a short description of the methods used and comprehensive student feedback that has been collected during the delivery of this workshop in this new academic course 2017/18 after some improvements.

\section{METHODOLOGY}

\subsection{Research-led workshop}

The research-led workshop consisted of the development of an intervention programme for an outbreak impacting the UK related with CCFH virus as it is a Category A emerging pathogen [12] currently threatening Western countries in Europe [13]. Contrarily to previous year, the workshop was delivered in different mini-group sessions due to the large number of students $(n=194)$ enrolled this academic course 2017/18. Students followed the different steps described in the evidence-based public health methodology [14] to identify appropriate measures for protection, preparedness and intervention. Students were provided with scientific papers and appropriate guidance documents to inform their decisions to develop their plan - we introduced recent articles published in the literature for which identification of interventions were clearly. Groups showed their intervention programme to the classroom by selecting a presenter or "peer teacher" in each group [15]. Each presenter provided a rationale for each measure considered and discussed why their intervention was appropriate and effective in addressing the proposed scenario.

\subsection{Questionnaires}

To explore the effectiveness of this novel training in facilitating the acquisition of some of the basic competences created to respond to biological incidents [which have been described in six domains by Peña-Fernández et al. (2016) [2], we have distributed the same validated feedback-questionnaire. The questionnaire has a series of questions related to the training in a Likert scale as well as some openquestions (free-response) so participants can comment on their overall experience and suggest improvements so we can use it to make appropriate modifications to this training. The Research Ethics Committee at De Montfort University provided ethical permission to perform this project (Ref. 1729). 


\section{RESULTS}

Only 73 out of the 194 students completed the questionnaire appropriately (38\% response rate); we discharged those that were partially completed. The results can be found in Table 1 below. In general, the specialised training was overwhelming well-received by BMS students, as evidenced by their favourable evaluation. Thus, high levels of satisfaction have been reported by participants $93 \%$ (63.2\% agreed; $29.8 \%$ strongly agreed). Moreover $86.3 \%$ of students $(58.9 \%$ agreed; $27.4 \%$ strongly agreed) highlighted that they enjoyed the research-led workshop delivered.

Table 1. Responses to the feedback-questionnaire to evaluate the improved training implemented in Medical Microbiology (BMS, DMU) to face biological incidents (in \%).

\begin{tabular}{|c|c|c|c|c|c|}
\hline Question & $\begin{array}{c}\text { Strongly } \\
\text { Disagree }\end{array}$ & Disagree & $\begin{array}{c}\text { Neither agree nor } \\
\text { disagree }\end{array}$ & Agree & $\begin{array}{c}\text { Strongly } \\
\text { agree }\end{array}$ \\
\hline $\begin{array}{c}\text { The content was relevant to the } \\
\text { module }\end{array}$ & 0.0 & 0.0 & 8.2 & 56.2 & 35.6 \\
\hline $\begin{array}{c}\text { The duration of the workshop was } \\
\text { appropriate }\end{array}$ & 0.0 & 0.0 & 5.5 & 57.5 & 37.0 \\
\hline $\begin{array}{c}\text { I am satisfied with the workshop } \\
\text { provided }\end{array}$ & 0.0 & 0.0 & 7.0 & 63.2 & 29.8 \\
\hline $\begin{array}{c}\text { Overall, I enjoyed the exercises } \\
\text { prevention/preparedness against a } \\
\text { biological incident }\end{array}$ & 0.0 & 0.0 & 13.7 & 58.9 & 27.4 \\
\hline $\begin{array}{c}\text { I gained adequate knowledge of } \\
\text { public health }\end{array}$ & 0.0 & 0.0 & 6.9 & 63.0 & 30.1 \\
\hline $\begin{array}{c}\text { I have learnt how to establish some } \\
\text { public health interventions to } \\
\text { protect the human health in a } \\
\text { biological incident }\end{array}$ & 0.0 & 0.0 & 5.2 & 63.2 & 31.6 \\
\hline
\end{tabular}

The research-led workshop developed would be successful in providing biomedical science students with some skills to respond to biological incidents, skills that were created and taken into account to develop the specialised training as described previously in Peña-Fernández et al. (2016) [2]. This would be supported by the fact that $93.1 \%$ of students that completed the questionnaire indicated that they acquire some knowledge of public health prevention and preparedness against a biological incident (63\% agreed; $30.1 \%$ strongly agreed; Table 1 ). Moreover, $94.8 \%$ pointed out that they learnt how to establish some public health interventions to protect humans in the aftermath of a biological incident $(63.2 \%$ agreed; $31.6 \%$ strongly agreed; Table 1$)$. These results are in concordance with those found previously with DMU biomedical science students from the 2016/17 cohort, as described in Peña-Fernández et al. (2017) [10].

Finally, students indicated the short time and large number of articles to read through as a constraint in the workshop delivered. They have also reported that they would like the delivery of similar workshops and training in other modules within their programme [ $86 \%$ (63.2\% agreed; $22.8 \%$ strongly agreed)].

\section{CONCLUSIONS}

The results gathered would indicate that the research-led workshop developed could be successful in providing biomedical science students with specific skills to respond to biological incidents, some of them very important such as the establishment of appropriate protection measures in the event of a biological incident or an outbreak of infection. Although more analysis will be needed, we have observed similar results when delivering this workshop to the last two academic courses.

To our knowledge, this is the first time that basic training to respond to biological incidents has been introduced in a biomedical science programme. The methods and training developed at DMU could be easily adapted to provide similar training on responding to biological incidents in other human health science programmes, which has become critical to protect the public. 


\section{REFERENCES}

[1] QAA (2015). Subject Benchmark Statement: Biomedical Sciences. Available at: http://www.qaa.ac.uk/en/Publications/Documents/SBS-Biomedical-sciences-15.pdf [accessed on $23 / 01 / 18]$

[2] Peña-Fernández A., Dunford LJ., Haris PI., Lobo-Bedmar MC., Peña MA. Harmonising the training of students within the EU to implement intervention programmes to protect the public in the aftermath of a HazMat incident. ICERI2016 Proceedings; pp. 3559-3565.

[3] Peña-Fernández A., Zinsky R., Choi E., Broadbent AJ. Developing training to prepare human health science students to face biological incidents. INTED2017 Proceedings 2017; pp. 47074714.

[4] Peña-Fernández A., Ollero MD., Fenoy S., Magnet A., Izquierdo F., Peña MÁ., Bornay F., Acosta L., Parker LA., Sgamma T., Del Águila C. Creating a model module for the novel resource DMU e-Parasitology. ICERI2017 Proceedings; 1599-1604. ISBN: 978-84-697-6957-7.

[5] Baize S, Pannetier D, Oestereich L, Rieger T, Koivogui L, Magassouba N, et al. Emergence of Zaire Ebola virus disease in Guinea. N Engl J Med 2014; 371(15):1418-25.

[6] WHO. Ebola Situation Reports. Available at: http://apps.who.int/ebola/ebola-situation-reports [accessed 25/01/2018]. Peña-Fernández A., Zinsky R., Choi E., Broadbent AJ. Developing training to prepare human health science students to face biological incidents. INTED2017 Proceedings 2017; pp. 4707-4714.

[7] Sandström BE, Eriksson H, Norlander L, Thorstensson M, Cassel G. Training of public health personnel in handling CBRN emergencies: a table-top exercise card concept. Environ Int. 2014; 72:164-9.

[8] Bell, B.P., Damon, I.K., Jernigan, D.B., Kenyon, T.A., Nichol, S.T., O'Connor, J.P., Tappero, J.W. Overview, control strategies, and lessons learned in the CDC response to the 2014-2016 Ebola epidemic. Morbidity and Mortality Weekly Report (MMWR) Suppl. 2016; 65(3):4-11.

[9] Djalali A, Della Corte F, Segond F, Metzger MH, Gabilly L, Grieger F, Larrucea X, Violi C, Lopez $C$, Arnod-Prin P, Ingrassia PL. TIER competency-based training course for the first receivers of CBRN casualties: a European perspective. Eur J Emerg Med. 2016, in press. DOI: 10.1097/MEJ.0000000000000383

[10] Peña-Fernández A., Escalera Izquierdo B., Peña MA. Evaluating basic training for prevention and response to biological incidents. In: Research in university teaching. Designing the future based on educational innovation. Roig-Vila, Rosabel (ed.). Barcelona: Octaedro, 2017; pp. 358366. ISBN 978-84-9921-935-6.

[11] Peña-Fernández A., loannou M., Lobo-Bedmar MC., Fenoy S. Curriculum modifications for teaching parasitology and infectious diseases in a Biomedical Science degree. ICERI2017 Proceedings; 1593-1598. ISBN: 978-84-697-6957-7.

[12] National Institute of Allergy and Infectious Diseases. NIAID Emerging Infectious Diseases/Pathogens website. Available at: https://www.niaid.nih.gov/research/emerginginfectious-diseases-pathogens [accessed on 23/01/18]

[13] England, M.E., Phipps, P., Medlock, J.M., Atkinson, P.M., Atkinson, B., Hewson, R., Gale, P. (2016). Hyalomma ticks on northward migrating birds in southern Spain: Implications for the risk of entry of Crimean-Congo haemorrhagic fever virus to Great Britain. Journal of Vector Ecology, 41(1), 128-34.

[14] Brownson R.C., Gurney J.G., Land G.H. Evidence-based decision making in public health. Journal of Public Health Management and Practice 1999; 5:86-97.

[15] Benè K.L. and Bergus G. When learners become teachers: a review of peer teaching in medical student education. Family Medicine 2014; 46(10):783-7. 